\title{
FORECASTING CHINA'S ECONOMIC GROWTH AND INFLATION
}

\author{
PATRICK HIGGINS, TAO ZHA, AND WENNA ZHONG
}

\begin{abstract}
Although macroeconomic forecasting forms an integral part of the policymaking process, there has been a serious lack of rigorous and systematic research in the evaluation of out-of-sample model-based forecasts of China's real GDP growth and CPI inflation. This paper fills this research gap by providing a replicable forecasting model that beats a host of other competing models when measured by root mean square errors, especially over long-run forecast horizons. The model is shown to be capable of predicting turning points and to be usable for policy analysis under different scenarios. We find that M2 supply, rather than interest rates, is a key variable for forecasting macroeconomic variables. It predicts that annual GDP growth for the next five years will be close to the $6.5 \%$ official target and that a future GDP growth path will be of L-shape rather than U-shape.
\end{abstract}

Date: August 7, 2016.

Key words and phrases. Out of sample, density forecasts, policy projections, scenario analysis, probability bands, random walk, Bayesian priors.

JEL classification: E10, E40, C53.

Copyright (c) 2014-2016 by Higgins, Zha, and Zhong. Comments from two referees and Todd Clark have helped improve the paper. We thank Chun Chang, Xiang Deng, and Zhao Li for helpful discussions. We are especially grateful to Giorgio Primiceri for providing his computer code and to Yandong Jia at the People's Bank of China, who has generously offered insights into the Chinese data and the practice of China's monetary policy. This research is supported in part by the National Science Foundation Grant SES 1558486 through the NBER and by the National Natural Science Foundation of China Research Grants 71473168 and 71473169 . The views expressed herein are those of the authors and do not necessarily reflect the views of the Federal Reserve Bank of Atlanta, the Federal Reserve System, or the National Bureau of Economic Research. 


\section{INTRODUCTION}

China's growth and cyclical fluctuations, especially since the 2008 financial crisis, have largely depended on China's macroeconomic policies. In particular, the government's policies for promoting investment in heavy industries such as real estate and infrastructure constitute a driving force behind both growth and cyclical fluctuations for the past two decades (Chang, Chen, Waggoner, and Zha, 2016). The question of where China's economic growth will be headed in the future (in the Chinese government's language, a L-shape or U-shape growth pattern) has been a hotly contested issue for policymakers and researchers alike.

As China has become the second largest economy in the world, rigorous and systematic research in the evaluation of out-of-sample forecasts of China's macroeconomy is urgently needed. ${ }^{1}$ For the Federal Reserve System and a number of central banks in other developed countries, macroeconomic forecasting is an integral part of the policymaking process. In this context, timely policy projections based on monthly macroeconomic time series are a research area that needs to be developed.

In this paper, we extend the Bayesian vector autoregression (BVAR) methodology to forecasting China's macroeconomy, especially gross domestic product (GDP) growth and consumer price index (CPI) inflation (the two variables exclusively considered by many central banks around the world for taking monetary policy actions). Our proposed benchmark model outperforms a host of other alternatives, including the gold-standard random walk model and other forecasting models studied in the recent literature. The model is close to the one used to provide forecasts for the People's Bank of China and the macro forecasting team at the Shanghai University of Finance and Economics. Our methodology enables one to generate density forecasts in addition to point forecasts. In this paper, we use 68 probability bands as the most commonly used device for communicating density forecasts.

Replicable forecasting models like our benchmark model are needed because their forecast performance can be evaluated in a scientific manner and on a continual basis. Some models, such as China's Annual Macroeconomic Model developed jointly by the Chinese Academy of Social Science and the National Bureau of Statistics of China (CASS-NBS) and China's Quarterly Macroeconomic Model developed by Xiamen University in 2006 (CQMM), do not have complete information about model structures for independent evaluation. In this paper, we restrict ourselves to a host of competing models that can be replicated and evaluated independently. One exception is the widely used monthly surveys of Blue Chip Economic Indicators (BCEI). Although the BCEI does not have replicable models, it provides a complete set of forecast records that can be used for comparison of forecast accuracy.

\footnotetext{
${ }^{1}$ Another area that needs more studies relates to the widening distribution of income as well as consumption in China. See Ding and He (2016) and the references therein.
} 
According to the root mean square error (RMSE) criterion, our benchmark model performs remarkably well over the long-run forecast horizon (three and four years ahead). Given the long lag of monetary policy, the long-run forecasting performance is particularly critical for policy analysis. We find that the model is also capable of predicting a turning point for GDP growth and CPI inflation, a challenging task for any macroeconomic model. We consider different policy scenarios to show that M2 growth, a policy instrument that has been utilized by the People's Bank of China in conducting its monetary policy, has proven to be very effective in predicting GDP growth in both short and long runs.

For the U.S. economy, forecasting inflation from replicable models is a top priority for policymakers and academic researchers (Stock and Watson, 2007). For China, forecasting GDP growth from replicable models is the most important factor for policy analysis as well as in an analysis of China's impact on the world economy. But model-based forecasts of China's GDP growth have proven to be challenging. In this paper we demonstrate that while our proposed benchmark model is competitive with other models in predicting CPI inflation, it is this model's superior performance in predicting GDP growth rates that warrants particular attention.

Recent policy discussions have centered on whether Chinas future GDP growth will be of L-shape rather than U-shape. Using the data up to the time when this paper is written, our estimated benchmark model predicts that Chinas real GDP growth for the next five years will be around $6.6 \%$ annually. Given the past growth path, this predicted growth pattern is of L-shape. The Thirteenth Five-Year Plan (2016-2020) approved by the National People's Congress of China makes $6.5 \%$ the real GDP growth target for the next five years. Our model prediction indicates that such an ambitious plan is feasible.

The rest of paper is structured as follows. Section II reviews the methodology for the benchmark model and the related literature on forecasting models. Section III describes the monthly data used in this paper. Section IV compares the forecast accuracy of our benchmark model to the competing models and explore the role of monetary policy using conditional forecasts. Section V performs a robustness analysis. Section VI uses our benchmark model to forecast future GDP growth to shed light on recent policy debates on whether economic growth in the future will be of L-shape versus U-shape. Section VII concludes the paper.

\section{Methodology And the Literature Review}

In this section we review the methodology of our benchmark model and then discuss other methods in the context of the literature. A brief description of this methodology, tailored to our own applications, is a self-contained material for the reader who is unfamiliar with the literature or does not want to read through the multiple original papers. 
II.1. The benchmark model. Our benchmark model is a Bayesian vector autoregression (BVAR) based on Waggoner and Zha (1999) with the Sims-Zha prior (Sims and Zha, 1998). It has the following VAR form:

$$
\sum_{l=0}^{p} y_{t-l}^{\prime} A_{l}=d^{\prime}+\epsilon_{t}^{\prime}, \text { for } t=1, \ldots, T,
$$

where $y_{t}$ is an $n \times 1$ vector of endogenous variables for period $t, T$ the sample size, $A_{l}$ an $n \times n$ coefficient matrix for the $l^{\text {th }}$ lag of the VAR, $p$ the number of lags, $d$ an $n \times 1$ vector of constant terms, and $\epsilon_{t}$ an $n \times 1$ vector of i.i.d. structural shocks satisfying

$$
E\left(\epsilon_{t} \mid y_{t-s}, s>0\right)=0 \text { and } E\left(\epsilon_{t} \epsilon_{t}^{\prime} \mid y_{t-s}, s>0\right)=I_{n}
$$

In this paper, since we focus on forecasting, we follow the convention of Sims (1980) and Christiano, Eichenbaum, and Evans (1999) make the contemporaneous coefficient matrix $A_{0}$ triangular. Unlike Christiano, Eichenbaum, and Evans (1999), however, the order of the variables is inconsequential for our forecasting exercises because only the reduced form matters for forecasting. The reduced form of (1) is

$$
y_{t}^{\prime}=c^{\prime}+\sum_{l=1}^{p} y_{t-l}^{\prime} B_{l}+e_{t}^{\prime}, \text { for all } t,
$$

where $c=A_{0}^{\prime-1} d, B_{l}=-A_{l} A_{0}^{-1}$ for $l=1, \ldots, p, e_{t}=A_{0}^{\prime-1} \epsilon_{t}$, and $\Sigma=E\left(e_{t} e_{t}^{\prime} \mid y_{t-s}, s>0\right)=$ $A_{0}^{\prime-1} A_{0}^{-1}$.

Define $\mathbf{Y}=\left[y_{1} y_{2} \ldots y_{T}\right]^{\prime}, \mathbf{y}=\operatorname{vec}(\mathbf{Y}), x_{t}=\left[y_{t-1}^{\prime} y_{t-2}^{\prime} \ldots y_{t-p}^{\prime}, 1\right]^{\prime}, \mathbf{X}=\left[x_{1} x_{2} \ldots x_{T}\right]^{\prime}$, $\mathbf{B}=\left[B_{1}^{\prime} B_{2}^{\prime} \ldots B_{p}^{\prime} c\right]^{\prime}, \mathbf{b}=\operatorname{vec}(\mathbf{B}), \mathbf{E}=\left[e_{1} e_{2} \ldots e_{T}\right]^{\prime}$, and $\mathbf{e}=\operatorname{vec}(\mathbf{E})$. The reduced form (2) can be rewritten in matrix form

$$
\mathbf{Y}=\mathbf{X B}+\mathbf{E}
$$

or

$$
\mathbf{y}=\left(I_{n} \otimes \mathbf{X}\right) \mathbf{b}+\mathbf{e}, \mathbf{e} \sim N\left(0, \Sigma \otimes I_{T}\right),
$$

where $N(\cdot, \cdot)$ represents a normal probability distribution.

We implement the Sims-Zha prior for the reduced-form (3) as

$$
\mathbf{b} \mid \Sigma \sim N(\overline{\mathbf{b}}, \bar{\Psi}) \text { and } \Sigma^{-1} \sim \widetilde{W}(\bar{S}, \bar{V}),
$$

where $\widetilde{W}(\cdot, \cdot)$ denotes a tractable distribution similar but not equal to the Wishart distribution. ${ }^{2}$ The vector $\overline{\mathbf{b}}=\operatorname{vec}\left(\left[I_{n}, \mathbf{0}_{n \times(n(p-1)+1)}^{\prime}\right]^{\prime}\right)$ reflects prior beliefs that each variable follows a random walk. The prior hyperparameter matrix $\bar{S}$ is an $n \times n$ diagonal matrix $\operatorname{diag}\left(\sigma_{1}, \sigma_{2}, \ldots, \sigma_{n}\right)$, where $\sigma_{i}$ is set to the standard deviation of the residuals from estimating a

\footnotetext{
${ }^{2}$ The prior parameter matrix $\bar{V}$, the exact probability density form for $\widetilde{W}(\cdot, \cdot)$, and how to sample from it are discussed in Sims and Zha (1998).
} 
univariate $\operatorname{AR}(p)$ fit by ordinary least squares to the time series of the $i^{\text {th }}$ variable. The hyperparameters $\lambda_{0}, \lambda_{1}, \lambda_{3}$, and $\lambda_{4}$ determine the prior diagonal covariance matrix $\bar{\Psi} .^{3}$ For each of $n^{2} p$ combinations of variable $i$, equation $j$, and lag length $l(1 \leq i \leq n, 1 \leq j \leq n, 1 \leq l \leq p)$, $\left[\lambda_{0} \lambda_{1} /\left(\sigma_{j} l^{\lambda_{3}}\right)\right]^{2}$ is the prior variance appearing at position $(i-1)[n p+1]+(l-1) n+j$ on the diagonal of $\bar{\Psi}$. The term appearing at position $i[n p+1]$ on the diagonal of $\bar{\Psi}$, for each $i$ with $1 \leq i \leq n$, is $\left[\lambda_{0} \lambda_{4}\right]^{2}$ (the prior variance on the constant term).

The most important part of the Sims-Zha prior consists of two sets of dummy observations from the data to capture prior beliefs about unit roots (not just random walk) and cointegration in the time series. We call this component of the prior "the cointegration prior," which turns out to be paramountly important because many of the Chinese time series tend to be highly cointegrated. The unit-root prior is mathematically expressed as the following $n$ dummy observations

$$
Y_{u r}=\mu_{5} \operatorname{diag}(\bar{y}) \text { and } X_{u r}=\mu_{5}\left[\mathbf{1}_{1 \times n} \otimes \operatorname{diag}(\bar{y}), \mathbf{0}_{n \times 1}\right]
$$

where the subscript "ur" stands for unit root, $\bar{y}=\frac{1}{p} \sum_{t=-(p-1)}^{0} y_{t}$ is the average of the initial $p$ observations, and $\mu_{5}$ is a prior hyperparameter. As $\mu_{5} \rightarrow \infty$, the prior implies a unit root in each equation with no cointegration. The cointegration prior is implemented with one dummy observation:

$$
Y_{c o}=\mu_{6} \bar{y} \text { and } X_{c o}=\mu_{6}\left[\mathbf{1}_{1 \times n} \otimes \bar{y}, 1\right]
$$

where the subscript "co" stands for cointegration and $\mu_{6}$ is a hyperparameter. As $\mu_{6} \rightarrow \infty$, the prior implies that the variables have up to $n-1$ cointegration relationships but allows for a single or multiple stochastic trends. Define $\mathbf{X}^{*}=\left[\mathbf{X}^{\prime}, X_{u r}^{\prime}, X_{c o}^{\prime}\right]^{\prime}$ and $\mathbf{Y}^{*}=\left[\mathbf{Y}^{\prime}, Y_{u r}^{\prime}, Y_{c o}^{\prime}\right]^{\prime}$. Posterior estimation is based on $\mathbf{Y}^{*}$ and $\mathbf{X}^{*}$ (not $\mathbf{Y}$ and $\mathbf{X}$ ).

Li (2016) applies the Sims-Zha prior to a large set of China's quarterly time series and find that a decay value of $\lambda_{3}$ as large as 5 is the key to achieving robust results of accurate outof-sample forecasts of GDP growth and CPI inflation. The standard Sims-Zha prior for the monthly U.S. time series, as documented by Zha (1998), is composed of $\lambda_{0}=0.57, \lambda_{1}=0.13$, $\lambda_{3}=1.0, \lambda_{4}=0.1$, and $\mu_{5}=\mu_{6}=10$. We call it the SZ-US prior. By combining Li (2016)'s new finding for China with the standard Sims-Zha prior, we propose the following values of hyperparameters for our monthly benchmark model: $\lambda_{0}=0.57, \lambda_{1}=0.13, \lambda_{3}=5.0$, $\lambda_{4}=0.1$, and $\mu_{5}=\mu_{6}=10$.

\footnotetext{
${ }^{3}$ The hyperparameter $\lambda_{2}$ with value 1 is used to map the prior on structural form parameters to the prior on reduced form parameters.
} 
II.2. Conditional forecasts. Given equation (2) and the data up to time $T$, the $h$-step ahead forecast at time $T$ is

$$
y_{T+h}^{\prime}=\underbrace{c^{\prime} K_{h-1}+\sum_{l=1}^{p} y_{T+1-l}^{\prime} N_{l, h}}_{\text {Unconditional forecast: } y_{T+h}^{u \prime}}+\underbrace{\sum_{k=1}^{h} \epsilon_{T+k}^{\prime} M_{h-k}}_{\text {Cumulative responses }},
$$

where

$$
\begin{gathered}
K_{0}=I_{n}, K_{i}=I_{n}+\sum_{k=1}^{i} K_{i-k} B_{k}, i=1,2, \ldots, h-1 ; \\
N_{l, 1}=B_{l}, N_{l, j}=\sum_{k=1}^{j-1} N_{l, j-k} B_{k}+B_{j+l-1}, l=1, \ldots, p ; j=2, \ldots, h ; \\
M_{0}=A_{0}^{-1}, M_{i}=\sum_{k=1}^{i} M_{i-k} B_{k}, i=1, \ldots, h-1 ;
\end{gathered}
$$

with the convention $B_{k}=\mathbf{0}$ for $k>p$.

The last term in (4) gives the cumulative impact of future structural shocks on endogenous variables through the impulse responses $M_{i}$. When restrictions are imposed on future values of certain variables, the forecasts generated by (4) are called conditional forecasts. Suppose we would like to constrain a scenario of letting the $n h \times 1$ vector of forecasts $\left[y_{T+1}^{\prime} y_{T+2}^{\prime} \ldots y_{T+h}^{\prime}\right]^{\prime}$ follow a particular path represented by $y^{*}=\left[y_{T+1}^{* \prime} y_{T+2}^{* \prime} \ldots y_{T+h}^{* \prime}\right]^{\prime}$. We stack unconditional forecasts from (4), from 1 step ahead through $h$ steps ahead, in the vector $y^{u}=\left[y_{T+1}^{u \prime} y_{T+2}^{u \prime} \ldots y_{T+h}^{u \prime}\right]^{\prime}$ and define $r=y^{*}-y^{u}$. We stack the corresponding impulse responses into the matrix $R$ as

$$
R=\left[\begin{array}{cccccc}
M_{0} & M_{1} & M_{2} & \ldots & M_{h-2} & M_{h-1} \\
0 & M_{0} & M_{1} & \ldots & M_{h-3} & M_{h-2} \\
\ldots & \ldots & \ldots & \ldots & \ldots & \ldots \\
0 & 0 & 0 & \ldots & M_{0} & M_{1} \\
0 & 0 & 0 & \ldots & 0 & M_{0}
\end{array}\right]
$$

By collecting the future structural shocks from $T+1$ to $T+h$ in the vector $\epsilon=\left[\epsilon_{T+1}^{\prime} \epsilon_{T+2}^{\prime} \ldots \epsilon_{T+h}^{\prime}\right]^{\prime}$, one can see from equation (4) that imposing the condition $y^{*}$ on the future forecasts is equivalent to imposing the following condition on the structural shocks

$$
R^{\prime} \epsilon=r .
$$

Now suppose we wish to impose only a subset of $y^{*}$. We first determine the row numbers of $y^{*}$ associated with the restricted subset and then remove other rows from $r$ and $R^{\prime}$. We use what is left to create $\tilde{r}$ and $\tilde{R}^{\prime}$. Thus, imposing a subset of restrictions is equivalent to 
imposing the condition

$$
\tilde{R}^{\prime} \epsilon=\tilde{r}
$$

Waggoner and Zha (1999) show that maximum likelihood estimate of $\epsilon$ subject to restriction (5) is $\epsilon^{M L E}=\tilde{R}\left(\tilde{R}^{\prime} \tilde{R}\right)^{-1} \tilde{r}$. These shocks are fed into (4) to generate the desired conditional forecasts.

II.3. Other models in the literature. It is known that BVAR forecasts are more accurate than VAR forecasts (Doan, Litterman, and Sims, 1984). While the literature on the BVAR methodology is voluminous, Robertson and Tallman (2001) and Carriero, Clark, and Marcellino (2015) discuss it in great details (see other references therein). BVAR models provide an important tool that has long been used by central banks around the world for macroeconomic analysis. There are several variations of BVAR modeling. The most popular one is the BVAR with the Minnesota prior introduced by (Litterman, 1986), whose model generated out-of-sample forecasts as accurate as those used by the best known commercial forecasting services. The Minnesota prior is a special case of the SZ-US prior without the unit-root and cointegration components.

Bańbura, Giannone, and Reichlin (2010) modify the Minnesota prior for relatively large BVAR models and propose a procedure to adjust a key value of the "overall tightness" hyperparameter as the number of variables increases. The prior proposed by Bańbura, Giannone, and Reichlin (2010) is further modified by Giannone, Lenza, and Primiceri (2015), who implement a more systematic approach by choosing a very diffuse prior for the hyperparameterscalled hyperpriors - and solving for the posterior mode of these hyperparameter values. Furthermore, they incorporate the Sims-Zha dummy observations for co-integration in their prior. With this systematic procedure, Giannone, Lenza, and Primiceri (2015) find that their 22-variable BVAR model has forecast accuracy comparable to their 3-variable and 8variable BVARs. ${ }^{4}$ A recent paper by the same authors (Giannone, Lenza, and Primiceri, 2014) propose another way of constructing a prior that incorporates long-run behaviors of time series. We use the priors proposed by both Giannone, Lenza, and Primiceri (2015) (called the GLP prior) and (Giannone, Lenza, and Primiceri, 2014) (called the PLR prior), which are the most recent priors proposed in the literature, to compare forecast accuracy to our benchmark model.

Popular alternative models in the forecasting literature include autoregressive (AR) models for each variable and the random walk model of Atkeson and Ohanian (2001) for each

\footnotetext{
${ }^{4}$ Specifically, the 22-variable BVAR's one year ahead forecast of GDP growth is less accurate than the smaller BVARs, but the one year ahead inflation forecast is more accurate.
} 
variable. For the $i^{\text {th }}$ variable, the various AR specifications studied in this paper are

$$
y_{t}^{i}=\alpha+\beta t+\sum_{l=1}^{p} \gamma_{l} y_{t-l}^{i}+u_{t}
$$

where $p=1,6,12, y_{t}^{i}$ is univariate, and $\beta=0$ whenever a trend is not used. The random walk model is often treated as the gold standard for out-of-sample forecasting. The original Atkeson and Ohanian (2001) model for foracasting the 12-month inflation rate is $E_{t}\left[\log \left(\frac{p_{T+12}}{p_{T}}\right)\right]=\log \left(\frac{p_{T}}{p_{T-12}}\right)$ (see equation (4) of their paper), where $p_{T}$ denotes the monthly price level at the end of the sample T. To implement Atkeson and Ohanian (2001)'s model, one would use the model $\hat{y}_{t+1}=\hat{y}_{t}+\frac{y_{T}-y_{T-12}}{12}$ for $t>T$, but we modify their approach by calculating the random walk forecast for the $i^{\text {th }}$ variable in one month ahead as ${ }^{5}$

$$
\hat{y}_{t+1}^{i}=\hat{y}_{t}^{i}+\left(\hat{y}_{t}^{i}-\hat{y}_{t-12}^{i}\right) / 12
$$

or equivalently

$$
\hat{y}_{t+1}^{i}-\hat{y}_{t}^{i}=\left(\hat{y}_{t}^{i}-\hat{y}_{t-12}^{i}\right) / 12 \text {. }
$$

When $t \leq T$ where $T$ is the date prior to the forecast period, $\hat{y}_{t}^{i}=y_{t}^{i}$. Multiple-step forecasts can be computed recursively. It turns out that the RMSEs produced by the original Atkeson and Ohanian (2001) model are larger than those from our modified random walk model (6) except for the two years ahead forecast of CPI inflation, although the differences are very small. Thus, we report results from our modified model.

II.4. Annual changes according to calendar year. Following the convention of reporting comparable forecasts established by the BCEI, we calculate the annual rate as the ratio of the average value in the forecast year to the average value in the previous year. This reporting method applies to GDP growth, CPI inflation, M2 growth, and other growth variables, except interest rates and variables that are already expressed in percent. To be consistent with calendar years, the time subscript $t$ can be alternatively expressed by double indices as $t=\{y r$, mon $\}$, where yr represents calendar year and mon represents calendar month. An annual growth rate expressed in percent is calculated as

$$
g_{y r, m o n}^{i}=100\left[\frac{\frac{\sum_{m o n=1}^{12} \exp \left(\hat{y}_{y r, m o n}^{i}\right)}{12}}{\frac{\sum_{m o n=1}^{12} \exp \left(\hat{y}_{y r-1, m o n}^{i}\right)}{12}}-1\right] .
$$

Let the first forecast date be $T+1=\left\{y r^{*}, m o n^{*}\right\}$. If $y r<y r^{*}$ or if $y r=y r^{*}$ but $m o n<$ mon $^{*}$, then $\hat{y}_{y r, m o n}^{i}=y_{y r, m o n}^{i}$. That is, the forecast value is the same as the actual value for those sample periods. Following the literature on forecast comparison, we use the RMSE metric to measure the accuracy of $g_{y r, m o n}^{i}$ against the actual growth rate.

\footnotetext{
${ }^{5}$ Other adapted random walk models include Stock and Watson (2007) and Ang, Bekaert, and Wei (2007).
} 


\section{DATA}

Our monthly dataset is based on Higgins and Zha (2015) and Chang, Chen, Waggoner, and Zha (2016), who construct a standard set of quarterly macroeconomic time series comparable to those commonly used in the macroeconomic literature on Western economies. The main data source is the CEIC's China Premium Database, which compiles China's official macroeconomic time series.

One may question the quality of China's official macroeconomic data, especially the GDP series. Despite the unsettled debates on this issue, our view is that one should not abandon the official series of GDP in favor of other less comprehensive series such as value added of industry, electricity consumption, or electricity production, no matter how "reliable" one would claim those alternatives are in gauging the pulse of China's overall economy. After all, the series of GDP is what financial markets, researchers, policy analysts, and policymakers have paid most attention to when assessing China's aggregate activity. In a very recent paper, Nie (2016) forcibly argues that "official GDP figures remain a useful and valid measure of Chinese economic growth."

The sample for estimation in this paper is from 2000M1 to the date prior to the forecast (starting 2010M12 and rolling forward to 2015M11 month by month), except in Section V whereby we use a longer sample period with fewer available variables to examine the robustness of our results. The number of evaluation points is 60 for one-year forecasting and 24 for four-year forecasting. We choose the year 2000 as the beginning of the sample because it represents a regime-switching point at which the People's Bank of China had begun to make M2 growth an explicit policy instrument for conducting monetary policy. The lag length is chosen to be 13 months with the presence of the thirteenth month to take account of any possible residual seasonality.

The monthly variables used for this paper are real value-added GDP that is interpolated, real retail sales of consumer goods (consumption), real fixed-asset investment (investment), M2, CPI, net exports (as percent of GDP), the 7-day market rate for national interbank bond repurchases (the repo rate), and the one-year benchmark deposit rate (the deposit rate). Real consumption is deflated by the CPI and real investment is deflated by the investment price index. $^{6}$ All variables are entered in log except for net exports and the two interest rates, which are entered as percentages divided by 100. Appendix A provides a description of how these monthly series are collected and constructed.

\footnotetext{
${ }^{6}$ Our results are very similar if one divides nominal consumption and investment by the GDP price deflator.
} 


\section{Assessing FORECASt PERFormanCE}

Models usable for day-to-day policy analysis must be able to forecast the economy well. The most important variables concerning Chinese policymakers are GDP growth and CPI inflation. ${ }^{7}$ Providing accurate forecasts of these two variables has proven to be an extremely challenging task. We show that our benchmark model performs remarkably well in comparison to a host of competing models studied in the literature and in most cases outperform the alternatives, as reported in Tables 1-4.

In addition to the benchmark model and the BCEI forecasts, we consider 12 competing models: (i) the gold-standard random walk model, (ii) the BVAR model with the SZ-US prior, (iii) the BVAR model with the PLR prior, (iv) the BVAR model with the GLP prior, (v) the popular BVAR model with the Minnesota prior, (vi) the widely used no-prior (standard) VAR model that can be estimated simply by ordinary least squares, and (vii) six univariate AR models, that is, $\mathrm{AR}(1), \mathrm{AR}(6)$, and $\mathrm{AR}(12)$ models with and without trend.

IV.1. Out-of-sample forecasting. Out-of-sample forecast RMSEs reported in Tables 1-4 are annual growth rates of real GDP and annual inflation rates of CPI. Except the BCEI forecasts, all the models listed in the tables use the sample starting from 2000M1 until the date when actual out-of-sample forecasts are made. The forecast year ranges from one year ahead (short-run) to four years ahead (long-run). Long-run forecasts have proven to be a difficult and oftentimes embarrassing exercise. For this and other reasons, the BCEI provides out-of-sample forecasts over only the horizon of two years. For policymakers, however, longrun out-of-sample forecasts are essential because monetary policy is known to have long and lagged effects on the real economy (Sims and Zha, 2006). We report the average of the BCEI forecasts, ${ }^{8}$ which are available for the forecast horizon of only two years, but for other models we report forecasts over the horizon of four years.

The forecast evaluation period is from 2011 to 2015. Since data are monthly and forecasts are updated each month, this five-year period gives us enough data points to evaluate out-ofsample forecast performance without disproportionately shortening the length of the sample used for accurate estimation. For this evaluation period, we compute the RMSEs of forecasts of GDP growth and CPI inflation at each forecast horizon (from one to four years ahead), reported in Tables 1-4.

\footnotetext{
${ }^{7}$ The two variables, output growth and inflation, are used by central banks around the world to guide their policy actions. In particular, the Summary of Economic Projections regularly released in the Federal Open Market Committee minutes by the Federal Reserve Board reports the projections of these two variables in addition to the unemployment rate and the federal funds rate under appropriate monetary policy.

${ }^{8}$ Bauer, Eisenbeis, Waggoner, and Zha (2006) show that the average BCEI forecast tends to be more accurate than individual forecasts.
} 
IV.2. GDP growth and CPI inflation. We first analyze forecasts from all models bar the BCEI, which is not model-based and will be discussed in the later part of the section. From Table 1 one can see that the benchmark model and the SZ-US model are very competitive; in comparison, the benchmark model fares worse in the short run and better in the long run. Except for the one year forecast horizon, the benchmark beats the random walk model and the AR(12) model without trend. The benchmark model outperforms all other models, with the popular Minnesota BVAR, the widely used no-prior VAR, and various AR models with trend faring much worse in longer forecast horizons (Table 1).

For CPI inflation, one can see from Table 2 that the SZ-US model is highly competitive with the benchmark model; the SZ-US model fares much better for the one-year forecast horizon and only slightly worse over longer forecast horizons. Although the SZ-US model is competitive with the benchmark model, we show in Section $\mathrm{V}$ that it is substantially worse in forecasting inflation when we extend both sample and evaluation periods. For the oneyear forecast horizon, there are a number of other models that beat the benchmark model: random walk, PLR, GLP, Minnesota, and all the AR models except AR(1) without trend. But for longer forecast horizons, the benchmark model outperforms all of them.

Since the literature regards the random walk model as the gold standard for gauging the success of other models in forecasting performance, Tables 3 and 4 report the ratio of the RMSE for each model to the RMSE for the random walk model. If the relative RMSE ratio for a particular model is greater than one, the model performs worse than the random walk model. If the ratio is less than one, the model performs better. Thus, the smaller the relative RMSE ratio, the better the corresponding model's performance. All models other than the benchmark and SZ-US models fail to beat the random walk model, especially over longer forecast horizons (Table 3). In comparison to the benchmark model, the random walk model performs better only over the one year horizon; it gives in to the benchmark model's increasing strength in all other forecast horizons (over two to four years ahead).

The results for CPI inflation, however, present a completely different picture. In addition to the benchmark model, a number of other models outperform the random walk model in the longer run (two to four years ahead), including the SZ-US model, the PLR model, and all AR models bar AR(1) and AR(12) without trend (Table 4). In fact, the SZ-US, PLR, and benchmark models, as well as $\mathrm{AR}(6)$ and $\mathrm{AR}(12)$ models with trend, beat the random walk model by large margins over longer forecast horizons. This phenomenon is in sharp contrast to the findings for the U.S. economy where the random walk model is the king for predicting inflation (Atkeson and Ohanian, 2001). For the Chinese economy, therefore, it is real GDP growth that is difficult to predict from parametric and replicable models.

Now we turn to the BCEI forecasts, which are not model-based but nonetheless merit discussion. On a monthly basis, the Blue Chip surveys 15-20 respondents on forecasting the 
Chinese economy. All respondents are top professional forecasters and most of them do not strictly adhere to a replicable econometric model. For GDP growth, their forecasts are often judgmentally chosen to be close to the target set by the Chinese government. This strategy pays off as the BCEI forecast of GDP growth fares better than our benchmark model as well as all other models, including the random walk model (Tables 1 and 3). But forecasting CPI inflation is a different matter. Although the Chinese government discusses what the CPI inflation target should be, monetary policy has been primarily used to support real GDP growth (Chen, Higgins, Waggoner, and Zha, 2016). As a result, the BCEI forecast of CPI inflation by closely following the government's rhetoric turns out to be much worse than the forecast produced by the benchmark model (Tables 2 and 4).

IV.3. In the aftermath of the global financial crisis. In 2009 the Chinese government injected an unprecedented four trillion RMB into the economy, which undoubtedly helped stabilize real GDP growth and pushed it over double digits in 2010. Many economists were stunned by how fast China's economy could turn around so swiftly (in comparison to the U.S. economy with a long and slow recovery). Although few economists at the end of 2010 would have predicted a persistently slowing economy starting in 2011, the turning point is captured by our benchmark model.

As shown in Tables 5 and 6, the benchmark model predicts, out of sample, a persistent decline of GDP growth similar to the actual path of GDP growth. In contrast, the PLR model shows a U-shape pattern of GDP growth with double digits. For CPI inflation, the benchmark model under-predicts the outcome, the PLR model over-predicts. Consistent with this over-prediction is the PLR model's U-shape prediction of growth rates of investment and M2, a direction opposite to the actual downward paths. The benchmark model, however, predicts the paths of investment growth and M2 growth in a downward direction similar to the actual paths.

Chen, Higgins, Waggoner, and Zha (2016) argue that the government is effective in controlling bank credit via M2 growth to influence investment and therefore GDP growth. The finding that M2 growth is a powerful policy instrument in China applies to this turning point as well. From Table 6 one can see that the benchmark model predicts a path of M2 growth lower than the actual path. This pattern supports the under-prediction of growth rates of investment and GDP.

Consider a policy scenario in which M2 growth follows the actual path in the forecast period 2011-2015. Using the technique of conditional forecasts discussed in Section II.2, we report the predictions of investment growth, CPI inflation, and GDP growth in Figure 1. Since the actual M2 growth path is higher than the unconditional forecast path (Table 6 and Figure 1), investment and GDP growth rates are higher than the unconditional counterparts 
( Tables 5-6 and Figure 1). As a result, the predicted path of GDP growth under this policy scenario is very close to the actual path, especially over longer forecast horizons (two to five years ahead). From the model's perspective, moreover, double-digit growth is unlikely because it is very close to the upper probability band of predictions.

In summary, the exercises in this section produce three findings. First, the benchmark model is capable of predicting the difficult turning point when economic growth turned into single digits after it rebounded to double digits in 2010 with the government's unprecedented expansionary monetary policy. Second, the policy variable, M2 growth, proves to be a powerful driving force of GDP growth. Third, the model can be effectively used for analyzing different policy scenarios.

\section{The ROLE OF A PRIOR AND ROBUStness ANALYSis}

In the preceding section we document evidence for the benchmark model's competitive performance. Several questions arise. Would the interpolated monthly GDP series underestimate the inherent monthly volatility and thus give distorted results? Why is the prior so important for out-of-sample forecasting? How robust are our results to a longer sample period? In this section we address these and other related questions.

Construction of monthly GDP data is recommended by Leeper, Sims, and Zha (1996) and Bernanke, Gertler, and Watson (1997) for the U.S. data. For the Chinese data, we follow the same strategy by using the relevant available monthly series published by the National Bureau of Statistics (NBS) of China as interpolaters. One critical interpolater is value added of industry, which measures the monthly activity in the manufacturing sector. Because the variable "value added of industry" is often used to approximate China's monthly output, the interpolated GDP series based on this series tracks by construction the volatility inherent in monthly data and would therefore deliver a more accurate measure of overall output in the economy. Indeed, the forecast results based on our interpolated monthly GDP data yield results similar to Li (2016), whose model is quarterly. One could in principle estimate a mixed-frequency model in state-space form. This is computationally more expensive and it is unclear whether it would necessarily improve out-of-sample forecasting ability in practice.

It is well known that an appropriate Bayesian prior is crucial for predictions out of sample. By appropriateness we mean to incorporate a crucial piece of the prior that captures beliefs that macroeconomic economic variables have common trends. This phenomenon is particularly true for the Chinese economy in which growth is driven by investment and accommodative monetary policy through rapid expansions of M2 growth. Without a prior, in-sample overfitting would be a serious problem for out-of-sample forecasting. This is one of the main reasons that parsimonious models such as random walk or various AR models 
tend to outperform regular (no-prior) VARs even though the latter may nest the former (Tables 1-4). When prior beliefs in unit roots and cointegrated relationships are incorporated, the model performs better than other alternatives without such a prior component (including the Minnesota model and the parsimonious models such as random walk), especially over longer forecast horizons.

The unit-root and cointegration component of the prior is central to out-of-sample forecasting even for longer samples. The main reason is that many variables in our model are nonstationary and are thus not so informative as econometricians would like, even for the U.S. data with longer samples. Robertson and Tallman (1999), for example, document that no-prior VARs are always much worse than various BVARs, with RMSEs roughly 50 to 100 percent higher for output growth and inflation over the two-year forecast horizon. Their estimation sample length is over 25 years. The prior, as a shrinkage device to pull uninformative data toward their inherent long-run behavior, improves the characterization of the likelihood (Sims and Zha, 1998).

As a robustness analysis, we extend our sample back to 1992M1 but with fewer variables. The monthly series available in 1992M1 are GDP, CPI, M2, investment, consumption, and the deposit rate. Because the investment price index series is unavailable prior to 1994M4, we use the GDP deflator to deflate nominal consumption and investment series. This longer sample length enables us to lengthen both estimation and evaluation periods. The estimation sample period is at least 15 years with the first period from 1992M1 to 2006M12. The evaluation period is from 2007 to 2015. Thus, compared to the analysis in Section IV, the number of evaluation points is increased from 60 to 108 for one-year forecasting and from 24 to 72 for four-year forecasting.

Tables 7-10 report the RMSEs produced with the longer sample and evaluation periods with fewer variables. The RMSEs for GDP growth and CPI inflation from the benchmark model are higher than the previous results partly because the data prior to 2000 belong to a different monetary policy regime and our model does not take into account this regime change. Nonetheless, the magnitude of RMSEs produced from the benchmark model is still small and indeed much smaller than that produced from the random walk model over forecast horizons longer than one year. The benchmark model performs worse than the BCEI for GDP growth but better than the BCEI for CPI inflation (Tables 7 and 8). The benchmark model performs much better than the PLR, GLP, and Minnesota models for GDP growth over forecast horizons longer than one year and for CPI inflation over all forecast horizons (except for the four-year forecast in which the Minnesota model beats the benchmark model). Th no-prior (regular) VAR model has in general a very poor forecasting performance relative to the benchmark model. 
Except the AR(1) model without trend, all other AR models perform worse than the benchmark model for GDP growth over forecast horizons longer than one year and for CPI inflation over all forecast horizons. The $\mathrm{AR}(1)$ model without trend represents the most parsimonious model and its parsimony pays off for forecasting GDP growth but fails badly for forecasting CPI inflation (compare Table 7 to Table 8). In general, the benchmark model's forecast performance is much more robust than the $\mathrm{AR}(1)$ model without trend in forecasting GDP growth (compare Table 1 to Table 7).

The SZ-US model performs much worse than the benchmark model in forecasting CPI inflation, but is again competitive in forecasting GDP growth. This competitiveness comes from the common feature shared by both the benchmark prior and the SZ-US prior: the substantial prior weight on possible cointegration relationships between real GDP and other macroeconomic variables. The weight on cointegration relationships is much stronger than what is implied by the PLR and GLP priors, which constitutes a major explanation of the benchmark model's success.

Besides the benchmark model, many other models, excluding GLP, Minnesota, and noprior VAR models but including almost all AR models, outperform the random walk model in forecasting GDP growth (Table 9). In forecasting CPI inflation, the random walk model is overtaken by many models, including almost all multivariate models such as the PLR and Minnesota models (Table 10). With all these changes in forecasting performance across models, a comparison between Tables 1-4 and Tables 7-10 shows that the benchmark model's superior performance in out-of-sample forecasting is robust to different sample and evaluation periods. There are two components or aspects of the Bayesian prior that help explain the Chinese monthly macroeconomic data: the speed of lag decay $\left(\lambda_{3}=5\right)$ and the weight on unit roots and cointegration relationships $\left(\mu_{5}=\mu_{6}=10\right)$. The long-run prior component has been standard for the U.S. data, but the large lag decay is a new discovery for the Chinese data.

\section{Into The FUtuRE: L-ShAPE VERSUS U-ShAPE OF GDP GROWTH}

Having established the benchmark model's superior performance of out-of-sample forecasts relative to other competing models, we now use the original model in Section IV to predict economic growth and inflation in the future. Such a prediction is informative because of its relevance to the current policy debate on whether China's GDP growth will be of U-shape or L-shape. Academic voice represented by Professor Daokui Li at Tsinghua, former member of Monetary Policy Committee of the People's Bank of China, expressed a view that China's GDP growth rate would likely be of U-shape. ${ }^{9}$ An official opinion has added to this academic

\footnotetext{
${ }^{9}$ See an interview with September 17, 2015 China Newsweek. The URL for that interview can be found at http://toutiao.com/i6195428846319583745/.
} 
voice. The press representative from the NBS, Laiyun Sheng, held a regular news conference on 15 April 2016 to express a similar view. ${ }^{10}$ On the other hand, People's Daily of 9 May 2016, an official newspaper representing the voice of the Central Communist Party, argued that future GDP growth would likely be of L-shape. ${ }^{11}$

Which prediction is likely to be more accurate and more consistent with the dynamics of the past data? Given considerable disagreements within the government itself, we use the benchmark model to shed light on this important policy debate at a critical juncture of the Chinese economy by providing forecasts to see which shape our prediction path is closer to. Figure 2 plots unconditional forecasts of GDP growth, CPI inflation, and M2 growth based on the information up to 2016M6. Tables 11 and 12 report the corresponding unconditional forecasts based on the posterior mode estimates. The .68 probability bands display a degree of uncertainty that reflects the historical forecast errors, with the lower probability band of GDP growth being as low as 3.5\%. But according to the most likely path (the path at posterior mode) most economists pay attention to, the model predicts a L-shape path of GDP growth that hovers around $6.6 \%$ over the next five years while CPI inflation is predicted to be $1.6 \%$ except for 2016 (in comparison, the BCEI forecast of GDP growth is $6.5 \%$ for 2016 and $6.2 \%$ for 2017 and of CPI inflation is $1.9 \%$ for 2016 and 2017). These results are in sharp contrast with those from the PLR model, which predicts CPI inflation as high as $2.7 \%$ by 2020 (Table 12) and a robust rebound of GDP growth from $7.1 \%$ in 2016 to $8.5 \%$ in 2020 (Table 11). The PLR model's forecast path of economic growth is certainly of U-shape. The predicted U-shape rebound, however, is so high that one may judge it a low probability event according to the upper probability band of GDP growth in Figure 2.

We use the benchmark model to analyze several policy scenarios. For the U.S. and other developed countries, the impact of interest rates on the aggregate real economy has proven to be powerful. The People's Bank of China has been planning to use interest rates such as the repo rate as a major policy instrument. Thus, it is informative to see how changes in future interest rates affect the Chinese economy. We consider a policy scenario in which the repo rate or the deposit rate would be raised by $1 \%$ above the unconditional forecasts to $3.5 \%$ for the repo rate and $2.5 \%$ for the deposit rate in from 2017 to 2020 . As one can see, the impact on GDP growth and CPI inflation in comparison to the unconditional forecasts is very limited (Tables 11 and 12). ${ }^{12}$ This finding, though not surprising for the

\footnotetext{
${ }^{10}$ See the NBS report at http: //www.stats.gov.cn/tjgz/tjdt/201604/t20160415_1344240. html as well as the report from China Economic Net at http://www.ce.cn/xwzx/gnsz/gdxw/ 201604/15/t20160415_10515154.shtml.

${ }^{11}$ See the link http://paper.people.com.cn/rmrb/html/2016-05/09/nw.D110000renmrb_ 20160509_6-01.htm\#.

${ }^{12}$ We have experimented with the lending rate instead of the deposit rate and the impact on GDP growth is even weaker.
} 
Chinese economiy, is contrary to the conventional wisdom about the impact of interest rates, a wisdom that is applicable to the U.S. and other developed economies.

Changes in M2 growth exert considerable impact on GDP growth as we illustrate in Section IV. Consider a policy scenario in which M2 growth will slow down from 12\% in 2016 to $10 \%$ in 2017 and then to $9 \%$ afterwards (in comparison to the unconditional forecast of $12.5 \%$ in 2016, $11.8 \%$ in 2017, and around $11.5 \%$ afterwards). ${ }^{13}$ Predicted CPI inflation is lower than the unconditional forecast path (Table 12). Future GDP growth is now predicted to be around $5.9 \%$ (Table 11), producing an even steeper L-shape trajectory. For our monthly dataset, the standard deviation is $3.79 \%$ for year-over-year M2 growth, $1.01 \%$ for the repo rate, and $0.64 \%$ for the deposit rate. In our various policy scenarios, therefore, changes in M2 growth from the unconditional forecasts are well within one standard deviation, while changes in the repo rate are about one standard deviation and changes in the deposit rate are well above one standard deviation. Yet, the impact of changes in M2 growth on GDP growth is much larger than that of changes in interest rates. A slowdown in M2 growth would be a sensible policy scenario to consider because it allows time for the People's Bank of China to transition from using M2 growth to using interest rates as a primary policy instrument.

\section{Conclusion}

We provide an empirical model for China's macroeconomy that can be replicated and evaluated independently. We show that this model has superior forecast performance relative to other competing models. Given this performance, the model should serve as a benchmark for comparison of policy projections and their forecast accuracy.

Accurate and timely macroeconomic forecasting is an essential part of the policymaking process. Contrary to the common belief based on the robust studies of the U.S. and other developed economies, we find that the impact of interest rates on the aggregate economy is relatively muted while changes in M2 growth have considerably larger impact. These findings imply that macroeconomic analysis of China should be built on these stylized facts, not on off-the-self models that have worked for other economies.

China's economy, as well as its monetary policy, has reached a stage that is mature enough for rigorous empirical macroeconomic analysis comparable to the international standards (Wen, 2016). In more ambitious projects for future research, for example, Markov-switching models taking into account of regime changes and stochastic volatility or mixed-frequency models incorporating daily financial variables would be useful tools to address many practical and policy-related issues.

\footnotetext{
${ }^{13}$ All conditional forecasts use the data available up to $2016 \mathrm{M} 6$.
} 
TABLE 1. RMSEs of GDP growth forecasts out of sample (percent)

\begin{tabular}{lcccc}
\hline \hline Model & Year 1 & Year 2 & Year 3 & Year 4 \\
\hline BCEI & 0.213 & 0.721 & na & na \\
Random walk & 0.414 & 1.128 & 1.369 & 1.856 \\
Benchmark & 0.467 & 0.983 & 0.990 & 0.735 \\
SZ-US & 0.349 & 0.816 & 1.035 & 1.226 \\
PLR & 0.500 & 1.538 & 2.185 & 2.740 \\
GLP & 0.578 & 1.693 & 2.182 & 2.578 \\
Minnesota & 0.772 & 2.650 & 3.414 & 4.122 \\
No-prior VAR & 0.622 & 2.898 & 5.838 & 9.832 \\
AR(1) without trend & 0.713 & 2.430 & 3.154 & 3.889 \\
AR(6) without trend & 0.655 & 2.289 & 2.970 & 3.670 \\
AR(12) without trend & 0.410 & 1.587 & 2.274 & 2.984 \\
AR(1) with trend & 1.557 & 4.525 & 4.112 & 3.874 \\
AR(6) with trend & 0.825 & 2.876 & 3.690 & 4.122 \\
AR(12) with trend & 0.770 & 3.162 & 4.582 & 4.449 \\
\hline
\end{tabular}

Note. The out-of-sample evaluation period is 2011-2015. The sample for estimation begins in 2000M1. The acronym "na" stands for "not available." 
TABLE 2. RMSEs of CPI inflation forecasts out of sample (percent)

\begin{tabular}{lcccc}
\hline \hline Model & Year 1 & Year 2 & Year 3 & Year 4 \\
\hline BCEI & 0.538 & 1.206 & na & na \\
Random walk & 0.261 & 1.613 & 1.932 & 2.673 \\
Benchmark & 0.467 & 0.632 & 0.643 & 0.332 \\
SZ-US & 0.235 & 0.716 & 0.652 & 0.387 \\
PLR & 0.284 & 1.038 & 1.046 & 1.510 \\
GLP & 0.375 & 1.906 & 2.588 & 3.523 \\
Minnesota & 0.461 & 1.812 & 2.425 & 3.106 \\
No-prior VAR & 1.178 & 2.694 & 3.707 & 4.414 \\
AR(1) without trend & 0.473 & 2.006 & 2.949 & 4.192 \\
AR(6) without trend & 0.300 & 1.300 & 1.817 & 2.561 \\
AR(12) without trend & 0.327 & 1.434 & 2.199 & 3.068 \\
AR(1) with trend & 0.415 & 1.341 & 1.625 & 2.005 \\
AR(6) with trend & 0.324 & 0.783 & 0.913 & 1.107 \\
AR(12) with trend & 0.320 & 0.857 & 1.043 & 1.354 \\
\hline
\end{tabular}

Note. The out-of-sample evaluation period is 2011-2015. The sample for estimation begins in 2000M1. The acronym "na" stands for "not available." 
TABLE 3. RMSEs (relative to random walk) of GDP growth forecasts out of sample

\begin{tabular}{lcccc}
\hline \hline Model & Year 1 & Year 2 & Year 3 & Year 4 \\
\hline BCEI & 0.564 & 0.640 & na & na \\
Random walk & 1.000 & 1.000 & 1.000 & 1.000 \\
Benchmark & 1.129 & 0.872 & 0.723 & 0.396 \\
SZ-US & 0.844 & 0.724 & 0.756 & 0.661 \\
PLR & 1.208 & 1.364 & 1.596 & 1.477 \\
GLP & 1.398 & 1.502 & 1.593 & 1.390 \\
Minnesota & 1.865 & 2.350 & 2.494 & 2.222 \\
No-prior VAR & 1.504 & 2.570 & 4.264 & 5.299 \\
AR(1) without trend & 1.722 & 2.155 & 2.304 & 2.096 \\
AR(6) without trend & 1.583 & 2.030 & 2.170 & 1.978 \\
AR(12) without trend & 0.992 & 1.408 & 1.661 & 1.608 \\
AR(1) with trend & 3.764 & 4.013 & 3.003 & 2.088 \\
AR(6) with trend & 1.993 & 2.551 & 2.696 & 2.221 \\
AR(12) with trend & 1.862 & 2.804 & 3.347 & 2.398 \\
\hline
\end{tabular}

Note. The out-of-sample evaluation period is 2011-2015. The sample for estimation begins in 2000M1. The acronym "na" stands for "not available." 
TABLE 4. RMSEs (relative to random walk) of CPI inflation forecasts out of sample

\begin{tabular}{lcccc}
\hline \hline Model & Year 1 & Year 2 & Year 3 & Year 4 \\
\hline BCEI & 2.064 & 0.748 & na & na \\
Random walk & 1.000 & 1.000 & 1.000 & 1.000 \\
Benchmark & 1.792 & 0.391 & 0.333 & 0.124 \\
SZ-US & 0.904 & 0.444 & 0.337 & 0.145 \\
PLR & 1.090 & 0.644 & 0.541 & 0.565 \\
GLP & 1.438 & 1.181 & 1.339 & 1.318 \\
Minnesota & 1.769 & 1.123 & 1.255 & 1.162 \\
No-prior VAR & 4.522 & 1.670 & 1.919 & 1.652 \\
AR(1) without trend & 1.815 & 1.243 & 1.526 & 1.568 \\
AR(6) without trend & 1.153 & 0.806 & 0.940 & 0.958 \\
AR(12) without trend & 1.257 & 0.889 & 1.138 & 1.148 \\
AR(1) with trend & 1.592 & 0.831 & 0.841 & 0.750 \\
AR(6) with trend & 1.243 & 0.485 & 0.473 & 0.414 \\
AR(12) with trend & 1.229 & 0.531 & 0.540 & 0.507 \\
\hline
\end{tabular}

Note. The out-of-sample evaluation period is 2011-2015. The sample for estimation begins in 2000M1. The acronym "na" stands for "not available." 
TABLE 5. Unconditional out-of-sample forecasts made at 2010M12 (percent)

\begin{tabular}{lccccccc}
\hline \hline & \multicolumn{3}{c}{ GDP growth } & & \multicolumn{3}{c}{ CPI inflation } \\
\cline { 2 - 3 } \cline { 6 - 8 } Horizon & Actual & Benchmark & PLR & & Actual & Benchmark & PLR \\
2006 & 12.7 & & & & 1.5 & & \\
2007 & 14.2 & & & & 4.8 & & \\
2008 & 9.7 & & & & 5.8 & & \\
2009 & 9.4 & & & & -0.7 & & \\
2010 & 10.6 & & & & 3.3 & & \\
\hline 2011 & 9.5 & 8.0 & 10.3 & & 5.4 & 3.4 & 5.6 \\
2012 & 7.9 & 6.0 & 10.0 & & 2.6 & 1.4 & 4.1 \\
2013 & 7.8 & 6.1 & 10.4 & & 2.6 & 1.4 & 3.7 \\
2014 & 7.3 & 6.1 & 10.5 & & 2.0 & 1.5 & 4.0 \\
2015 & 7.0 & 6.2 & 10.6 & & 1.4 & 1.5 & 4.3 \\
\hline
\end{tabular}

Note. The forecast period is from 2011 to 2015.

TABLE 6. Unconditional out-of-sample forecasts made at 2010M12 (percent)

\begin{tabular}{|c|c|c|c|c|c|c|}
\hline \multirow{3}{*}{$\begin{array}{l}\text { Horizon } \\
2006\end{array}$} & \multicolumn{3}{|c|}{ Investment growth } & \multicolumn{3}{|c|}{ M2 growth } \\
\hline & Actual & Benchmark & PLR & Actual & Benchmark & PLR \\
\hline & 21.7 & & & 18.1 & & \\
\hline 2007 & 20.2 & & & 17.6 & & \\
\hline 2008 & 15.5 & & & 16.7 & & \\
\hline 2009 & 33.7 & & & 26.6 & & \\
\hline 2010 & 20.1 & & & 20.6 & & \\
\hline 2011 & 18.9 & 19.5 & 21.2 & 14.6 & 13.4 & 15.6 \\
\hline 2012 & 19.3 & 12.9 & 22.3 & 13.6 & 10.2 & 16.8 \\
\hline 2013 & 19.3 & 13.1 & 23.2 & 14.8 & 10.3 & 18.5 \\
\hline 2014 & 14.6 & 13.2 & 23.0 & 13.0 & 10.4 & 18.5 \\
\hline 2015 & 12.2 & 13.3 & 22.8 & 12.3 & 10.5 & 18.5 \\
\hline
\end{tabular}

Note. The forecast period is from 2011 to 2015. 
TABLE 7. RMSEs of GDP growth forecasts out of sample (percent)

\begin{tabular}{lcccc}
\hline \hline Model & Year 1 & Year 2 & Year 3 & Year 4 \\
\hline BCEI & 0.558 & 0.908 & na & na \\
Random walk & 0.774 & 2.147 & 2.595 & 2.628 \\
Benchmark & 0.849 & 1.415 & 1.650 & 1.705 \\
SZ-US & 0.616 & 1.357 & 1.639 & 1.864 \\
PLR & 0.766 & 2.004 & 2.670 & 3.134 \\
GLP & 0.898 & 2.699 & 3.752 & 4.604 \\
Minnesota & 0.836 & 2.488 & 3.291 & 3.963 \\
No-prior VAR & 1.063 & 3.107 & 4.160 & 5.009 \\
AR(1) without trend & 0.710 & 1.061 & 1.305 & 1.491 \\
AR(6) without trend & 0.721 & 1.452 & 1.800 & 2.089 \\
AR(12) without trend & 0.678 & 1.845 & 2.313 & 2.593 \\
AR(1) with trend & 1.267 & 2.295 & 1.905 & 1.871 \\
AR(6) with trend & 0.832 & 1.463 & 1.715 & 1.910 \\
AR(12) with trend & 0.735 & 1.656 & 1.935 & 1.918 \\
\hline
\end{tabular}

Note. The out-of-sample evaluation period is 2007-2015. The sample for estimation begins in 1992M1. The acronym "na" stands for "not available." 
TABLE 8. RMSEs of CPI inflation forecasts out of sample (percent)

\begin{tabular}{lcccc}
\hline \hline Model & Year 1 & Year 2 & Year 3 & Year 4 \\
\hline BCEI & 0.798 & 2.324 & na & na \\
Random walk & 0.757 & 3.249 & 3.901 & 2.758 \\
Benchmark & 0.591 & 1.978 & 1.785 & 1.302 \\
SZ-US & 0.786 & 2.623 & 3.136 & 1.882 \\
PLR & 0.707 & 2.357 & 3.001 & 2.411 \\
GLP & 0.666 & 2.080 & 2.660 & 4.313 \\
Minnesota & 0.704 & 2.404 & 2.106 & 1.181 \\
No-prior VAR & 0.758 & 2.601 & 3.236 & 2.120 \\
AR(1) without trend & 1.111 & 3.335 & 3.311 & 3.412 \\
AR(6) without trend & 0.975 & 3.786 & 5.071 & 5.394 \\
AR(12) without trend & 0.983 & 3.849 & 5.361 & 5.873 \\
AR(1) with trend & 1.111 & 3.309 & 3.090 & 3.499 \\
AR(6) with trend & 0.709 & 2.290 & 2.531 & 2.612 \\
AR(12) with trend & 0.700 & 2.345 & 2.478 & 2.463 \\
\hline
\end{tabular}

Note. The out-of-sample evaluation period is 2007-2015. The sample for estimation begins in 1992M1. The acronym "na" stands for "not available." 
TABLE 9. RMSEs (relative to random walk) of GDP growth forecasts out of sample

\begin{tabular}{lcccc}
\hline \hline Model & Year 1 & Year 2 & Year 3 & Year 4 \\
\hline BCEI & 0.722 & 0.423 & na & na \\
Random walk & 1.000 & 1.000 & 1.000 & 1.000 \\
Benchmark & 1.097 & 0.659 & 0.636 & 0.649 \\
SZ-US & 0.796 & 0.632 & 0.632 & 0.710 \\
PLR & 0.990 & 0.933 & 1.029 & 1.193 \\
GLP & 1.161 & 1.257 & 1.446 & 1.752 \\
Minnesota & 1.081 & 1.159 & 1.268 & 1.508 \\
No-prior VAR & 1.374 & 1.447 & 1.603 & 1.906 \\
AR(1) without trend & 0.918 & 0.494 & 0.503 & 0.567 \\
AR(6) without trend & 0.933 & 0.676 & 0.694 & 0.795 \\
AR(12) without trend & 0.877 & 0.859 & 0.891 & 0.987 \\
AR(1) with trend & 1.638 & 1.069 & 0.734 & 0.712 \\
AR(6) with trend & 1.076 & 0.682 & 0.661 & 0.727 \\
AR(12) with trend & 0.950 & 0.771 & 0.746 & 0.730 \\
\hline
\end{tabular}

Note. The out-of-sample evaluation period is 2007-2015. The sample for estimation begins in 1992M1. The acronym "na" stands for "not available." 
TABLE 10. RMSEs (relative to random walk) of CPI inflation forecasts out of sample

\begin{tabular}{lcccc}
\hline \hline Model & Year 1 & Year 2 & Year 3 & Year 4 \\
\hline BCEI & 1.055 & 0.715 & na & na \\
Random walk & 1.000 & 1.000 & 1.000 & 1.000 \\
Benchmark & 0.781 & 0.609 & 0.458 & 0.472 \\
SZ-US & 1.039 & 0.807 & 0.804 & 0.682 \\
PLR & 0.934 & 0.725 & 0.769 & 0.874 \\
GLP & 0.881 & 0.640 & 0.682 & 1.563 \\
Minnesota & 0.931 & 0.740 & 0.540 & 0.428 \\
No-prior VAR & 1.002 & 0.801 & 0.830 & 0.768 \\
AR(1) without trend & 1.468 & 1.027 & 0.849 & 1.237 \\
AR(6) without trend & 1.288 & 1.165 & 1.300 & 1.956 \\
AR(12) without trend & 1.300 & 1.185 & 1.374 & 2.129 \\
AR(1) with trend & 1.469 & 1.019 & 0.792 & 1.268 \\
AR(6) with trend & 0.937 & 0.705 & 0.649 & 0.947 \\
AR(12) with trend & 0.925 & 0.722 & 0.635 & 0.893 \\
\hline
\end{tabular}

Note. The out-of-sample evaluation period is 2007-2015. The sample for estimation begins in 1992M1. The acronym "na" stands for "not available." 
TABLE 11. Into the future: GDP growth forecasts (percent)

\begin{tabular}{lccccc}
\hline \hline Horizon & Unconditional & PLR & On M2 & On repo & On deposit rate \\
2016 & 6.7 & 7.1 & 6.7 & 6.8 & 6.9 \\
2017 & 6.6 & 8.3 & 6.1 & 6.6 & 6.9 \\
2018 & 6.6 & 8.6 & 5.9 & 6.6 & 6.8 \\
2019 & 6.6 & 8.6 & 5.9 & 6.6 & 6.8 \\
2020 & 6.7 & 8.5 & 6.0 & 6.7 & 6.9 \\
\hline
\end{tabular}

Note: The forecasts are made with the estimation period 2000M1-2016M6.

"Unconditional" is the benchmark model's forecast. "On M2" indicates forecasts conditional on the path of slower M2 growth specified in the text, "On repo" indicates forecasts conditional on the path of higher repo rates specified in the text, and "On deposit rate" indicates forecasts conditional on the path of higher deposit rates specified in the text.

TABLE 12. Into the future: CPI inflation forecasts (percent)

\begin{tabular}{lccccc}
\hline \hline Horizon & Unconditional & PLR & On M2 & On repo & On deposit rate \\
2016 & 1.9 & 2.0 & 1.9 & 1.9 & 2.3 \\
2017 & 1.6 & 2.0 & 1.5 & 1.6 & 2.2 \\
2018 & 1.6 & 2.5 & 1.5 & 1.6 & 1.8 \\
2019 & 1.6 & 2.6 & 1.5 & 1.7 & 1.8 \\
2020 & 1.7 & 2.7 & 1.5 & 1.7 & 1.8 \\
\hline
\end{tabular}

Note. The forecasts are made with the estimation period 2000M1-2016M6. "Unconditional" is the benchmark model's forecast. "On M2" indicates forecasts conditional on the path of slower M2 growth specified in the text, "On repo" indicates forecasts conditional on the path of higher repo rates specified in the text, and "On deposit rate" indicates forecasts conditional on the path of higher deposit rates specified in the text. 

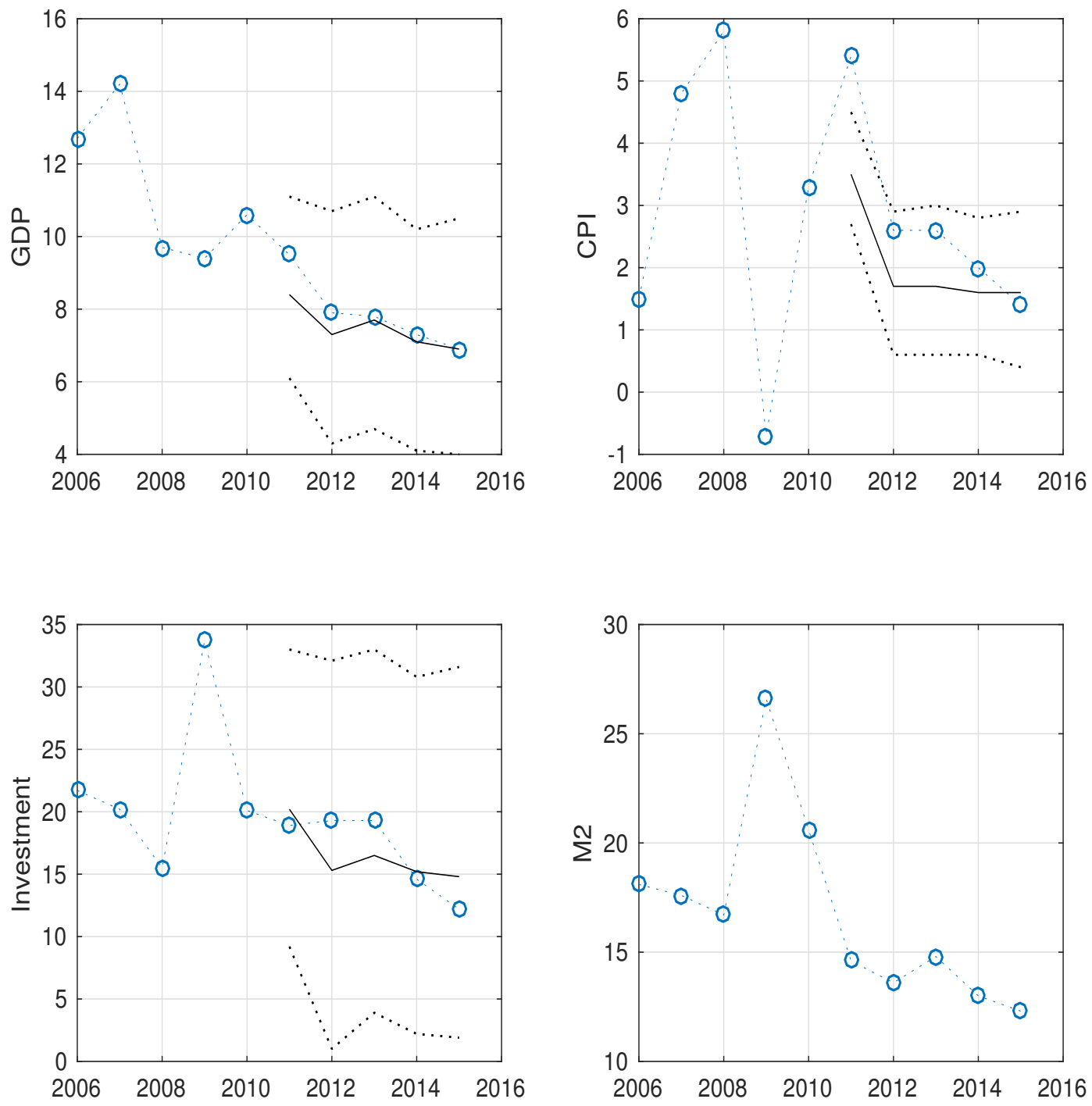

Figure 1. Out-of-sample forecasts made at 2010M12 with .68 probability bands (the dotted lines) conditional on the actual M2 path. Circle lines (from 2006 to 2015) indicate actual data and solid lines (from 2011 to 2015) represent forecasts at posterior mode. 

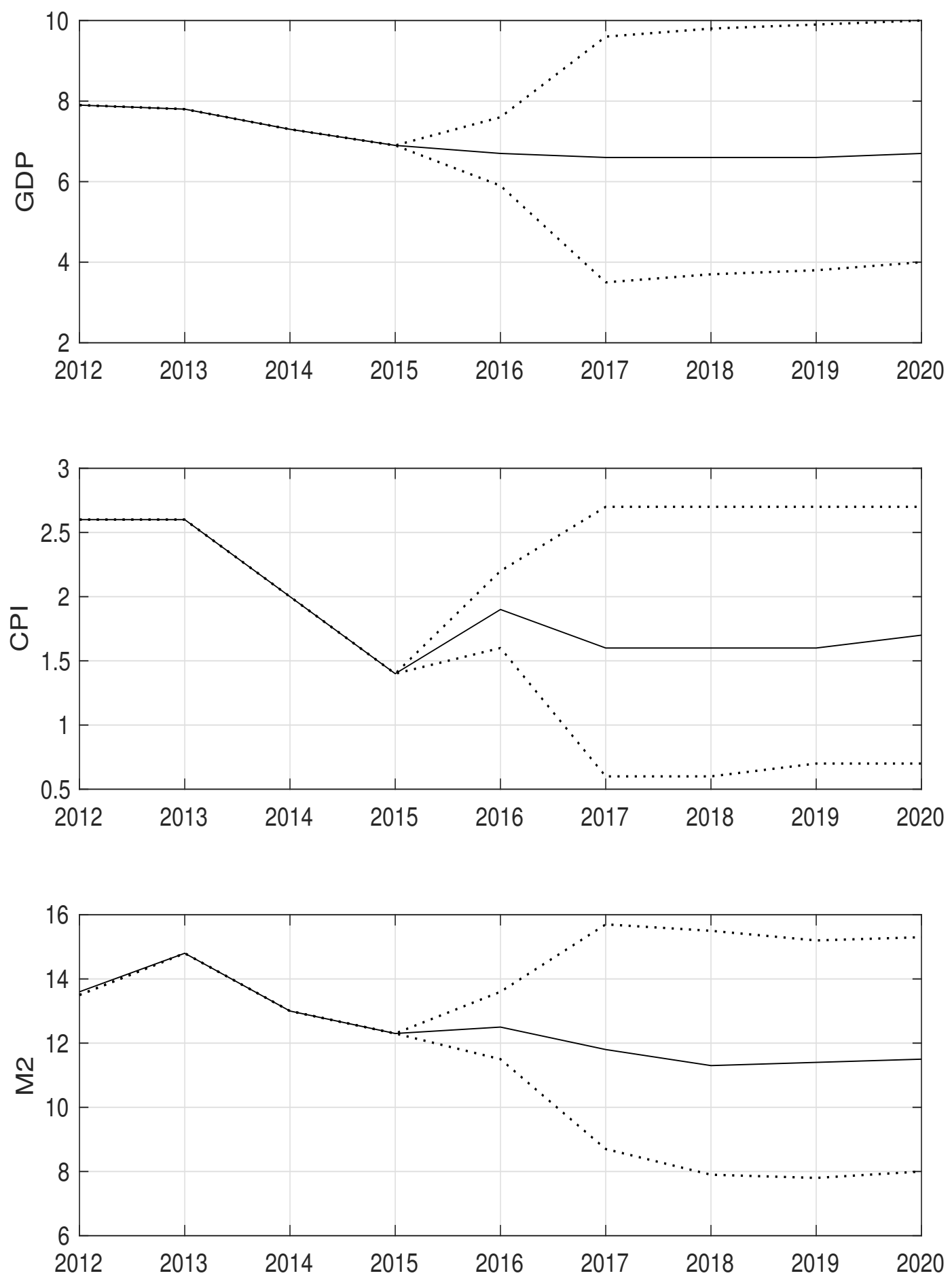

FigURE 2. Unconditional out-of-sample forecasts made at 2016M6 with .68 probability bands (the dotted lines). 


\section{Appendix A. Construction of monthly data}

Based on the seasonally adjusted quarterly series, our method of interpolating the monthly series follows closely Chow and Lin (1971) and Fernandez (1981). For the monthly series of nominal investment, nominal consumption, CPI, nominal imports, nominal exports, and value added of industry, the Chinese New Year effect brings about a special seasonality problem. The Chinese New Year holiday season has a substantial impact on monthly economic activity; it falls in January or February sometimes and crosses both months other times. There are three challenges for this type of seasonal adjustment. First, the published value is sometimes aggregated across January and February. Second, the value for December is often significantly higher than those for other months even after seasonal adjustment. Third, there are level shifts for some series (notably a level shift in the investment series during the year of 2004).

We tackle this problem with dummy regression variables. For the data since 2000, the dummies take the values of the number of days in the month when the Chinese New Year was observed less any extra working days added because of the long span of the Chinese New Year holidays. For other months that are not affected by the Chinese New Year holiday season, the dummies are small negative numbers (-5/11). This approach makes the sum of dummies each year equal zero so that the seasonally adjusted levels are consistent with the levels with no seasonal adjustments on an annual basis.

For the data prior to 2000, different dummies are used because the Chinese New Year, as Roberts and White (2015) note, changed from a 1-day holiday to a 5-day holiday in 2000. They also note that the seasonal impact of the Chinese New Year changed in 2000. Prior to 2000, a month has the Chinese New Year dummy value of 1 if it is the Chinese New Year month and $-1 / 11$ if it is not. The pre-2000 dummies are all 0 starting in 2000 and the post2000 dummies are all 0 before 2000. This seasonal adjustment method yield results similar to those produced by another seasonally adjusted method used for post-2000 time series. That method uses a combination of Fernald, Spiegel, and Swanson (2014)'s approach to disaggregating one January-February observation into two observations in separate months and Wright (2013)'s approach to seasonally adjusting the resulting series. Overall, our seasonal adjustment works well for taking account of the Chinese New Year effect. Figure A.1 plots the investment series before and after our adjustment. It is evident that the adjustment removes both seasonality and level shift.

We provide, below, a list of monthly variables we use for this paper and a brief description of how they are constructed.

Nominal GDP: We interpolate seasonally adjusted quarterly nominal GDP value added with seasonally adjusted monthly nominal retail sales of consumer goods, nominal 


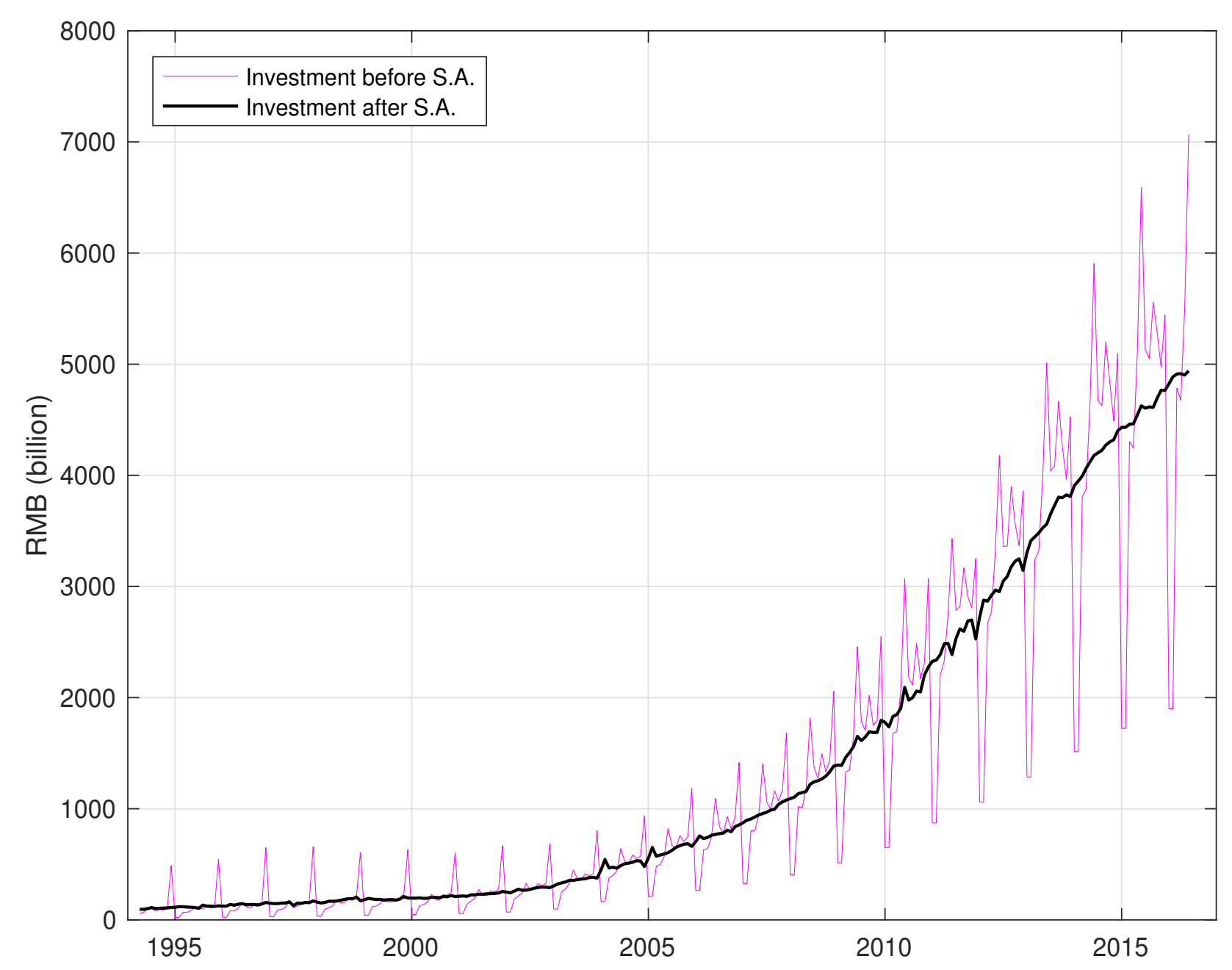

Figure A.1. Monthly series of fixed-asset investment.

exports, nominal imports, and nominal value added of industry. For data prior to 1995M10, where nominal value added of industry is not available, we use a slightly different set of interpolaters.

GDP deflator: This monthly series is constructed in two steps. In the first step, we interpolate the seasonally adjusted quarterly GDP deflator with the seasonally adjusted monthly series of producer price index (PPI), retail price index, CPI and M2. The PPI is only available since 1995M10 and thus it is not used for interpolation prior to this month. The first-step GDP deflator is used to construct monthly real GDP as described below. In the second step, the monthly series is derived by dividing monthly nominal GDP by monthly real GDP as constructed below.

Real GDP: This monthly series is constructed in two steps. In the first step, the monthly series is derived by dividing nominal GDP by the first-step monthly GDP deflator. In the second step, we perform an interpolation by constraining monthly real GDP to an quarterly aggregate equal to quarter real GDP. 
Nominal consumption: We seasonally adjust the monthly series of retail sales of consumer goods. Before the seasonal adjustment the January and February year-to-date value is disaggregated.

Nominal investment: We seasonally adjust both "capital construction + innovation" and total fixed-asset investment. The fixed-asset investment series starts in 1994 and the series for "capital construction + innovation" exists before 1994. We slice the two series, which gives rise to our investment series. The splice point is 1994. For this investment series, residual seasonality still exists because the January and February value needs be disaggregated and because a drop off in value after December is large. Hence, we perform a second round of seasonal adjustments using the X11-ARIMA method with its default settings. This additional adjustment eliminates much of the residual seasonality. ${ }^{14}$

Investment price index: Based on the the seasonally adjusted quarterly investment price series, the monthly series is interpolated with the producer price index whose inflation rates are highly correlated with inflation rates of the investment price, value added of industry, and CPI. The series, starting in 1996M1 and ending in 2016M6, is relatively reliable since 2004Q1 when the CEIC began to publish the quarterly series. Prior to 2004, we interpolate the annual investment price deflator with the PPI.

CPI: We seasonally adjust the monthly consumer price index series using the X-12 ARIMA method with regression dummies to account for the Chinese New Year effect.

M2: We derive the M2 level series from the level series from 2015M7 to 2016M6 and the year-over-year growth rates published by the People's Bank of China for all other months. This constructed series alleviates serious problems of sudden changes or misalignments of statistical coverage for certain periods of the sample. We then seasonally adjust this series with dummy regressors for the months so that the yearover-year growth rates are the same as the year-over-year for the original data prior to seasonal adjustment. This method works well because the seasonal factors in the M2 level series are stable during our sample period.

Nominal imports: The original monthly series is from the Chinese customs. The series is seasonally adjusted with the X-12 ARIMA method and with regression dummies to account for the Chinese New Year effect.

Nominal exports: The original monthly series is from the Chinese customs. The series is seasonally adjusted with the X-12 ARIMA method and with regression dummies to account for the Chinese New Year effect.

\footnotetext{
${ }^{14}$ Removing residual seasonality is a challenging task. In U.S. real GDP, for instance, residual seasonality still exists. See https://www.bea.gov/national/pdf/Residual\%20Seasonality\%20in\%20GDP\%20and\%20GDI.pdf for details.
} 
Repo rate: The 7-day market rate for national interbank bond repurchases. This is a market rate available since 1996M1.

Deposit rate: The one-year benchmark deposit rate set by the People's Bank of China. This series exists from 1988M10 on. 


\section{REFERENCES}

Ang, A., G. Bekaert, And M. Wei (2007): "Do Macro Variables, Asset Markets, or Surveys Forecast Inflation Better?," Journal of Monetary Economics, 54, 1163-1212.

Atkeson, A., and L. E. Ohanian (2001): "Are Phillips Curves Useful for Forecasting Inflation?," Federal Reserve Bank of Minneapolis Quarterly Review, 25(1), 2-11.

Bańbura, M., D. Giannone, and L. Reichlin (2010): "Large Bayesian Vector Autoregressions," Journal of Applied Econometrics, 25(1), 71-92.

Bauer, A., R. A. Eisenbeis, D. F. Waggoner, and T. Zha (2006): "Transparency, Expectations, and Forecasts," Economic Review, pp. 1-25, First Quarter.

Bernanke, B. S., M. Gertler, and M. W. Watson (1997): "Systematic Monetary Policy and the Effects of Oil Price Shocks," Brookings Papers on Economic Activity, 1, 91-142.

Carriero, A., T. E. Clark, and M. Marcellino (2015): "Bayesian VARs: Specification Choices and Forecast Accuracy," Journal of Applied Econometrics, 30(1), 46-73.

Chang, C., K. Chen, D. F. Waggoner, and T. Zha (2016): "Trends and Cycles in China's Macroeconomy," NBER Macroeconomics Annual, 30, 1-84, University of Chicago Press.

Chen, K., P. Higgins, D. F. Waggoner, And T. Zha (2016): "China's Pro-Growth Monetary Policy and Its Transmission," Unpublished Manuscript.

Chow, G. C., And A.-L. Lin (1971): "Best Linear Unbiased Interpolation, Distribution, and Extrapolation of Time Series by Related Series," The Review of Economics and Statistics, 53(4), 372-375.

Christiano, L. J., M. S. Eichenbaum, and C. L. Evans (1999): "Monetary Policy Shocks: What Have We Learned and To What End?," in Handbook of Macroeconomics, ed. by J. B. Taylor, and M. Woodford, vol. 1A, pp. 65-148. North-Holland, Amsterdam, Holland.

Ding, H., And H. He (2016): "A Tale of Transition: An Empirical Analysis of Economic Inequality in Urban China, 1986-2009," Unpublished Manuscript, International Monetary Fund.

Doan, T., R. B. Litterman, and C. A. Sims (1984): "Forecasting and Conditional Projection Using Realistic Prior Distributions," Econometric Reviews, 3(1), 1-100.

Fernald, J. G., M. M. Spiegel, and E. T. Swanson (2014): "Monetary Policy Effectiveness in China: Evidence from a FAVAR Model," Journal of International Money and Finance, 49(A), 83-103.

Fernandez, R. B. (1981): "A Methodological Note on the Estimation of Time Series," Review of Economics and Statistics, 63(3), 471-476. 
Giannone, D., M. Lenza, and G. E. Primiceri (2014): "Priors for the Long Run," Unpublished Manuscript.

(2015): "Prior Selection for Vector Autoregressions," The Review of Economics and Statistics, 97(2), 436-451.

Higgins, P. C., And T. Zha (2015): "China's Macroeconomic Time Series: Methods and Implications," Unpublished Manuscript, Federal Reserve Bank of Atlanta.

Leeper, E. M., C. A. Sims, And T. Zha (1996): "What Does Monetary Policy Do?," Brookings Papers on Economic Activity, 2, 1-78.

LI, Z. (2016): "Forecasting China's Economy: A Bayesian Approach," Unpublished Manuscript, Emory University.

Litterman, R. B. (1986): "Forecasting with Bayesian Vector Autoregressions - Five Years of Experience," Journal of Business and Economic Statistics, 4, 25-38.

NiE, J. (2016): "Gauging the Strenth of Chinese GDP Growth," The Macro Bulletin, pp. 1-3, http://macrobulletin.kcfed.org.

Roberts, I., And G. White (2015): "Seasonal Adjustment of Chinese Economic Statistics," Reserve Bank of Australia Research Discussion Paper 2015-13.

Robertson, J. C., and E. W. Tallman (1999): "Vector Autoregressions: Forecasting and Reality," Federal Reserve Bank of Atlanta Economic Review, First Quarter, 4-18.

- (2001): "Improving Federal-Funds Rate Forecasts in VAR Models Used for Policy Analysis," Journal of Business and Economic Statistics, 19(3), 324-330.

Sims, C. A. (1980): "Macroeconomics and Reality," Econometrica, 48(1), 1-48.

Sims, C. A., And T. Zha (1998): "Bayesian Methods for Dynamic Multivariate Models," International Economic Review, 39(4), 949-968.

(2006): "Does Monetary Policy Generate Recessions?," Macroeconomic Dynamics, 10, 231-272.

Stock, J. H., And M. W. Watson (2007): "Why Has U.S. Ination Become Harder to Forecast?," Journal of Money, Credit and Banking, 39(Supplement s1), 3-33.

Waggoner, D. F., And T. Zha (1999): "Conditional Forecasts in Dynamic Multivariate Models," The Review of Economics and Statistics, 81(4), 639-651.

Wen, Y. (2016): The Making of an Economic Superpower: Unlocking China's Secret of Rapid Industrialization. World Scientific Publishing Co.

Wright, J. H. (2013): "Unseasonal Seasonals?," Brookings Papers on Economic Activity, pp. 65-126, Fall.

ZhA, T. (1998): "A Dynamic Multivariate Model for Use in Formulating Policy," Federal Reserve Bank of Atlanta Economic Review, 83(1), 16-29, First Quarter.

Federal Reserve Bank of Atlanta; Federal Reserve Bank of Atlanta, Emory University, Sichuan University, and NBER; Shanghai Jiaotong University 